\title{
NARRATIVAS DE COMUNIDADES APRENDENTES EM EDUCAÇÃO AMBIENTAL
}

\author{
Maria do Carmo Galiazzi ${ }^{1}$, Diana Paula Salomão de Freitas ${ }^{2}$, Cleiva Aguiar de Lima ${ }^{3}$, \\ Claudia da Silva Cousin ${ }^{4}$, Moacir Langoni de Souza ${ }^{5}$, Rodrigo Launikas Cupelli ${ }^{6}$
}

\section{RESUMO}

Apresentamos a síntese de cinco pesquisas desenvolvidas pela Comunidade Aprendente em Educação Ambiental, Ciências e Matemática, da Universidade Federal do Rio Grande. Este Grupo de Pesquisaformação integra docentes da educação básica e do ensino superior que, pela escrita narrativa, leitura crítica e re-escrita das suas ações aprendem a ser e a se tornam uma comunidade. Os metatextos obtidos pela Análise Textual Discuriva são narrativas sobre a constituição de educadores ambientais que desenvolveram o sentimento de pertencimento, visando criticar modelos sociais baseados em hierarquias $\mathrm{e}$ individualismos, com o intuito de aprender a ser e a se tornar uma comunidade.

Palavras-chave: Educação Ambiental; Comunidade Aprendente; Narrativa.

\section{ABSTRACT}

This paper describes a synthesis of researches conducted in Environmental Education carried out by a group called Learning Communities in Environmental Education, Science and Mathematics from the Universidade Federal do Rio Grande. This research group bases its activities on action research with teachers, researchers and environmental educators. It focuses on critical written and reading texts of classroom recordings to problematise teaching practice of the participants. The group has used Textual Discourse Analysis in narratives of educational action concerning their development as environmental educators and in the development of the sense of belonging. All the researches aim at criticizing social

\footnotetext{
${ }^{1}$ Universidade Federal do Rio Grande - FURG. Escola de Química e Alimentos. Líder do grupo de pesquisa CEAMECIM. E-mail: mcgaliazzi@gmail.com

${ }^{2}$ Professora permanente do Programa de Pós-graduação em Ensino de Ciências - Mestrado Profissional e do Programa de Pós-graduação do Mestre em Educação Ambiental e Doutora em Educação em Ciências pela FURG. Vice-líder do Grupo de Pesquisa em Inovação Pedagógica na Formação AcadêmicoProfissional dos Profissionais da Educação.

${ }^{3}$ Professora do Instituto Federal de Educação, Ciência e Tecnologia do Rio Grande do Sul - IFRS Câmpus Rio Grande e do Programa de Pós-graduação em Educação em Ciências (PPGEC) da FURG. Líder do grupo de pesquisa em Educação Profissional e Tecnológica do Instituo Federal de Educação Tecnológica do Rio Grande do Sul - IFRS - Câmpus Rio Grande, doutora em Educação Ambiental.

${ }^{4}$ Professora permanente do Programa de Pós-graduação em Educação Ambiental - PPGEA da Universidade Federal do Rio Grande - FURG, Grupo de pesquisa CEAMECIM, doutora em Educação Ambiental pela FURG.

${ }_{6}^{5}$ Professor na Universidade Federal do Rio Grande - FURG, doutor em Educação Ambiental.

${ }^{6}$ Técnico ambiental da Divisão de Educação Ambiental da Itaipu Binacional, mestre em Educação Ambiental pelo PPGEA-FURG.
} 
models that are based on hierarchies and individuality. A new perspective proposes to be and learn how to become a learning community

Key words: Environmental Education; Learning Communities; Narrative.

\section{INTRODUÇÃO}

Neste texto apresentam-se sínteses de cinco (05) pesquisas realizadas em um grupo de pesquisa denominado de Comunidades Aprendentes em Educação Ambiental, Ciências e Matemática (CEAMECIM) do Programa de Educação Ambiental (PPGEA) da Universidade Federal do Rio Grande (FURG), único programa de pós-graduação em Educação Ambiental do Brasil. As pesquisas permitiram argumentar quanto à pertinência da formação de Comunidades Aprendentes (CA) que adotam a pesquisa narrativa como repertório para o desenvolvimento de práticas partilhadas em rodas de formação, pois o próprio processo de formação da $\mathrm{CA}$, a escuta dos participantes e a narrativa evidenciaram ser elementos transformadores na formação de professores educadores ambientais.

Assume-se que as CA são grupos que se organizam em torno de interesses comuns, estabelecendo relações de pertencimento intensificadas ao longo do tempo. Atuam em torno de objetivos coletivos, compartilhando preocupações, problemas e afetos, a partir de uma área de conhecimento ou de prática (Wenger, 2001; Lave e Wenger, 1991; Brandão, 1998).

Entende-se que essa perspectiva ajuda a efetivar espaços participativos de aprender a concretizar transformações epistemológicas, pois o foco do aprender passa de um sentido individual para uma perspectiva coletiva. Assume-se ainda a construção do conhecimento e elaboração da prática docente como processos dinâmicos e em permanente reconstrução, compreensão em sintonia com princípios de participação da Educação Ambiental e favorece o desenvolvimento de práticas mais complexas, a partir das diferenças e semelhanças percebidas dentro e fora da comunidade (Salomão de Freitas, 2010).

A esta perspectiva se agrega a pesquisa narrativa como elemento transformador na formação de educadores ambientais, pois a pesquisa narrativa parte do pressuposto que a vida é narrativa, e a pesquisa é o estudo da experiência como ela é vivida. Todos os 
procedimentos de pesquisa são produzidos tendo a narrativa como procedimento e orientação metodológica (Clandinin e Connely, 2000; Hart, 2005).

O texto a seguir apresenta sínteses resultantes de pesquisas realizadas no grupo de pesquisa CEAMECIM, apresentando categorias organizadoras no trabalho de formação de professores educadores ambientais: a roda de formação como repertório para a constituição de professores educadores ambientais (Lima 2011), a CA como organizadora de processos de formação de professores (Salomão de Freitas, 2010), o pertencimento ao lugar (Cousin, 2011), a possibilidade das narrativas ficcionais em uma CA de professores educadores ambientais (Cupelli, 2008) e a escuta como princípio de acolhimento da Educação Ambiental (Souza, 2010).

\section{A RODA DE FORMAÇÃO COMO REPERTÓRIO COMPARTILHADO DE PROFESSORES EDUCADORES AMBIENTAIS}

No CEAMECIM, se a pesquisa narrativa é modo de pesquisar em comunidades interpretativas e a CA um dos repertórios compartilhados, é a Roda de Formação (Souza, 2010) outra das apostas para a formação de professores educadores ambientais como apresentada a seguir a partir de pesquisa realizada no contexto da educação profissional (Lima, 2011) e no curso de Educação Ambiental Lato Sensu a distância, promovido pela FURG em parceria com o Sistema Universidade Aberta do Brasil (Cousin, 2010).

São diferentes as rodas ao longo da trajetória profissional de um professor. Aulas e reuniões em roda se configuram como um modo de organizar as pessoas para que possam dialogar entre si. Entretanto, o sentido formativo não é tão valorizado quanto a organização do espaço.

Desse modo, ainda que os encontros se deem em círculo, são denominados: reuniões, trabalho em grupo, discussões coletivas, não sendo considerados Rodas com a dimensão formativa que encerram. Como aponta Warschauer (2001:175): “as Rodas são espaços para o trabalho coletivo na escola", que se diferenciam das reuniões pela participação e pelas partilhas que envolvem a prática de planejar e avaliar as atividades e o próprio encaminhamento dos encontros. 
A compreensão da Roda de Formação de professores como uma opção políticoepistemológica tem seu fundamento em Paulo Freire. A proximidade da experiência da Roda de Formação com os Círculos de Cultura, propostos pelo autor, sucede da compreensão de que "ensinar inexiste sem aprender e vice-versa" (Freire, 2007a: 23). Nesse sentido, a disposição dos sujeitos ao diálogo, bem como o questionamento da verticalidade das relações tradicionalmente estabelecidas em processos de formação são problematizadas por uma nova organização espacial. Com base nisso, os Círculos de Cultura constituem-se em uma proposta formativa em que (Freire, 2006b) buscava superar os modelos tradicionais de alfabetização de adultos baseados em cartilhas infantis. Para o autor, substituir a escola carregada de passividade, pelo Círculo de Cultura, o professor com tradições "doadoras" pelo coordenador de debates, a aula discursiva pelo diálogo, os conteúdos de programas alienados por uma programação que problematizava a realidade, foram superações necessárias à época e ainda hoje.

Assumindo a perspectiva dos Círculos de Cultura, a Roda de Formação difere da reunião pelo sentido atribuído à partilha. A partilha pressupõe uma postura ética de dar e receber, no sentido de troca de promoção da aprendizagem mútua. Implica o falar e o silenciar, o diálogo com o outro, mas também consigo mesmo. "Viver a abertura respeitosa aos outros e, (...) tomar a própria prática de abertura ao outro como objeto de reflexão crítica" (Freire, 2007a: 136). E nesse sentido exercer a acolhida tantos às ideias dos outros quanto ao modo de manifestá-las.

O Círculo de Cultura pode ser reinvetado na Roda de Formação quando esta pressupõe o diálogo, que na perspectiva freireana assume a qualidade de ser “problematizador” e possibilita o repensar de si, de sua prática na relação dialógica com o pensar do outro e com outras práticas.

Com esse entendimento, o curso de Educação Ambiental Lato Sensu a distância, com duração de 360 horas, desenvolvido em cinco polos da Universidade Aberta do Brasil (UAB), em localidades distantes da sede, teve por objetivo promover a formação de professores pesquisadores no campo da Educação Ambiental, a partir da formação de 
dos alunos do curso - muitos professores em exercício no cordão litorâneo sulriograndense, no estado do Rio Grande do Sul, região sul do Brasil.

O curso orientou-se por uma formação propositiva, a partir da elaboração, planejamento, execução, registro e avaliação de um Projeto de Educação Ambiental desenvolvido na comunidade do aluno e acompanhado pelos professores por ambiente de aprendizagem específico (Plataforma Moodle). Foram ofertadas 60 vagas, e foram 49 os alunos concluintes. Pretendeu-se promover uma formação baseada no diálogo crítico sobre as questões ambientais.

A pesquisa buscou compreender os processos educativos que promoveram o sentimento de pertencimento e, concomitantemente os processos formativos em Educação a Distância - EaD (Cousin, 2010).

Utilizou-se a pesquisa narrativa como possibilidade de contar histórias vividas durante o processo de formação. Foram elaboradas narrativas ficcionais que expressam sentidos que emergiram da análise sobre os processos de formação com o intuito de apresentar as categorias emergentes na pesquisa, que foram: pertencimento ao lugar, que mostrou a forma como os aprendentes compreenderam e se relacionaram com o lugar onde vivem; os discursos de Educação Ambiental, que identificaram o pertencimento a este campo do conhecimento, tornando mais complexa a forma de compreendê-la; formação de educadores ambientais que discutiu a importância de compreender-se em processo de formação continuada. Apresenta-se a seguir um fragmento de uma das histórias produzidas a partir da análise.

\section{Tempo de areia e de livros...}

Fim de tarde ensolarado... Flávio observava da janela o movimento na orla da Lagoa dos Patos. O movimento era grande na Praia das Nereidas, marcando o início da temporada de verão.

Flávio caminhava devagar, observando lentamente a paisagem. Encontrou Helena. Sentaram-se às margens da Lagoa, à sombra de uma figueira. Tinham muitos 
AMBIENTE \& EDUCAÇ̃̃o

ISSN- 1413-8638

E-ISSN - 2238-5533

v. 22, n. 2, p. 129-153, 2017

momentos para recordar. Simularam uma autoavaliação de si e também do curso de Educação Ambiental a Distância, recém finalizado.

Helena no início pensava que o meio ambiente era simplesmente a natureza (animais e plantas).

- Com o passar do tempo comecei a ver as questões ambientais como um compromisso social. Entendi que estas não estão apenas em preservar espécies ou evitar a poluição do ar, dos rios, dos arroios, mas sim, com a qualidade de vida do ser humano. Para mim, Flávio, a Educação Ambiental deve tratar também das desigualdades sociais.

Flávio, ouvindo a colega falar sobre valores de igualdade, de respeito à diversidade de culturas, da valorização dos modos de vida das comunidades locais, afirmou convicto:

- É importante pensar que existem formas de viver, onde a base não é o consumo desenfreado, a exploração sem limites dos recursos naturais sob a ótica do lucro. Trabalho em escolas com realidades diferentes, uma no meio urbano e outra, no rural; embora o rural esteja cada vez mais parecido com o urbano, constatou enfático. Mas ao longo dos anos, percebi que os alunos não conhecem o lugar onde moram, e por isso, resolvi discutir na sala de aula os problemas ambientais do município.

Diferente de Helena, Flávio começou a trabalhar com a problemática ambiental recentemente. Para ele, os problemas ambientais estavam na produção de lixo, no assoreamento dos rios, na pesca predatória, no desmatamento. O curso acrescentou outra possibilidade:

- Hoje, compreendo que é importante realizar a discussão do local na sala de aula. Entendo que o local e o global estão relacionados e produzem modificações na configuração do lugar. Tive esta ideia, após ler alguns livros de Educação Ambiental. Tenho pensado muito sobre isto. A importância de trabalhar a história do lugar e os signos e símbolos que constituem sua identidade. Ou seja, a relevância de desenvolver um trabalho na sala de aula, que resgate a importância do Caminho Farroupilha, do Caminho Pomerano, o significado do caldo lourenciano para a cultura do lugar, o arroio São Lourenço, os aspectos que fazem parte da nossa história, que nos constituem 
e que, muitas vezes, são negligenciados por nós mesmos enquanto educadores. Para isto, precisei estudar e compreender melhor a história do município! E, só percebi esta lacuna quando tive que escrever a narrativa sobre "O município que temos e o município que queremos", proposta durante o curso.

Estavam envolvidos pela conversa que nem perceberam que anoitecia. Helena começou a sentir a brisa fria da lagoa. A lua crescente e a Lagoa dos Patos encantavam essa bela paisagem.

No sentido da história apresentada, a narrativa como artefato capaz de significar o processo de formação de educadores permitiu construir argumentos para compreender a formação de educadores ambientais na modalidade de EaD.

Foi possível defender que: a) os processos de formação em EA precisam intensificar e problematizar a importância de pertencimento ao lugar para a constituição de educadores ambientais; b) o exercício com professores de planejamentos de ações em EA e seu desenvolvimento, c) o registro desses processos formativos de forma narrativa, que se transformam em produção de material didático para trabalhar em cursos futuros de formação de professores educadores ambientais.

A educação a distância mostrou ser uma aliada da formação de professores educadores ambientais porque permitiu formar-se no lugar de atuação do professor educador ambiental, ou seja, o sentimento de pertencimento se intensificou à medida que possibilitou navegar no ambiente virtual, agir e narrar no lugar em que vivem e atuam os alunos do curso.

\section{FORMAÇÃO PERMANENTE DE PROFESSORES DE CIÊNCIAS EM COMUNIDADE APRENDENTE}

A pesquisa de Salomão de Freitas (2010) teve outro princípio constituidor em processos de formação de professores educadores ambientais: a função epistêmica da escrita (Freire, Faundez, 1985; Demo, 1995a; 1995b; 1996; 1997; 1998; 2000; Galiazzi, 2003; Moraes, Ramos, Galiazzi, 2004; Wells, 1999; Vygotsky, 1991). Nessa perspectiva buscou-se compreender o processo de formação de um grupo de professores de Ciências, iniciantes e experientes, que se reuniu semanalmente, durante um ano, a fim de continuar 
seu processo formativo colocando na Roda de Formação (Souza, 2010; Lima, 2011) suas práticas de sala de aula.

Partiu-se nessa pesquisa do pressuposto da necessidade de os professores educadores ambientais compreenderem-se como participantes de uma CA. Assumiu-se que processos formativos com essa conformação pautam-se pela consideração e valorização dos saberes e conhecimentos dos membros da comunidade, na intenção de partilhá-los e proporcionar-lhes aprendizagens (Wenger, 2001; Yus, 2002; Barton, Tusting, 2005; St. Clair, 2008).

Nessa Roda problematizou-se coletivamente o planejamento e desenvolvimento de Unidades de Aprendizagem (UA) em um enfoque que relacionou Ciência, Tecnologia e as suas implicações para a Sociedade (CTS). UA são modos de organização e desenvolvimento de atividades na sala de aula, a partir de temas de relevância do contexto dos alunos, em que a pesquisa é o princípio educativo que organiza a UA a partir das perguntas dos alunos e professores sobre esse tema (Moraes, Gomes 2007). O produto das UA foi sistematizado em artigos dos professores envolvidos submetidos, avaliados e discutidos em um evento anual de formação de professores - o Encontro sobre Investigação na Escola (EIE) - que acontece desde 2000 no Rio Grande do Sul, Brasil.

Os temas trabalhados nas UA foram pesquisas sobre conteúdos conceituais, a saber: a) o sangue; b) problemas ambientais relacionados ao lixo e a energia; d) resíduos da construção civil; e) produção de biocombustíveis; f) consumo desenfreado de aparelhos de celulares; g) mercado de trabalho para Técnicos em Eletrônica, h) refrigeração e conservação dos alimentos e i) modos de aprender a ser professor. Assuntos que evidenciaram a preocupação dos professores com temas pertinentes à crise socioambiental.

A partir da análise do registro das UA, identificou-se a presença de características que favoreceram a constituição de um grupo de professores em uma CA. A primeira delas consistiu em considerar a aprendizagem como uma experiência de transformação de identidade. As práticas de leitura, discussão e planejamento coletivo evidenciaram o empenho dos professores em relações que sempre envolveram o outro. Como disse uma 
das professoras do grupo, "essa forma de aprender em grupo nos faz crescer e melhorar as relações ao aceitar os outros e também suas contribuições".

A segunda característica esteve na articulação entre as atividades consideradas centrais e as consideradas periféricas. O grupo de professores constituiu-se como uma $\mathrm{CA}$, pois a maioria dos membros desenvolveu atividades consideradas centrais, como as UA, a escrita do texto para o EIE e sua participação nas reuniões semanais. Outros ficaram na periferia do grupo, o que pode ser percebido pelas faltas às reuniões semanais, a não participação nas discussões teóricas, a participação intensa apenas nas conversas nos intervalos.

A terceira característica da CA foi a combinação entre os modos de pertencimento à comunidade, o que dependeu das condições de desenvolvimento das atividades de se engajar, de imaginar e de conectar esforços de compreensão da problemática global com as repercussões que exerce no contexto local (Wenger, 2001). No planejamento e produção de UA coletivas observou-se o engajamento dos professores em proporcionar situações coletivas para aprender. Com relação ao trabalho de imaginação, quando os professores do grupo planejaram as atividades do semestre seguinte, elencando o que ler, como registrar e avaliar o processo de formação proposto aos seus alunos, eles imaginaram atividades a serem desenvolvidas.

Ao simular a efetividade de uma proposta, no plano das ideias, os professores desenvolveram possibilidades criativas de rompimento de um currículo disciplinar, criando situações de experiências (Larrosa, 2002) em sala de aula, a partir do desenvolvimento de um tema de relevância social. Sobre as condições para o trabalho, de buscar conectar esforços a compreensões mais complexas a cerca da problemática ambiental envolvida na UA, pareceu que a energia investida pelos professores favoreceu uma ação de educação ambiental pouco efetiva, ao colocar a responsabilidade no indivíduo e eximir de responsabilidade a estrutura social e o modo de produção capitalista (Loureiro, 2006).

Notou-se que os professores pouco problematizaram a relação entre o que abordavam nas UA com o contexto macropolítico e macroeconômico pertinente aos 
temas. Por exemplo, na UA que teve como objetivo constatar a validade do protótipo de um aquecedor solar construído com garrafas 'PET' e incentivar os alunos para serem multiplicadores dessa atividade, para com isso minimizar os problemas socioambientais com a utilização de materiais recicláveis, não foram problematizadas as razões da crise energética contemporânea. Trabalhou-se a partir de uma proposta ingênua de reversão do quadro de degradação socioambiental com a diminuição do consumo ou com mudanças de hábitos individuais, o que transfere a responsabilidade da crise ambiental para o indivíduo (Loureiro, 2004; 2006).

A quarta característica que faz do grupo uma CA foi a possibilidade dos membros reconfigurarem suas identidades e mudarem as posições dentro da comunidade. Nesse aspecto, observou-se que alguns professores não modificaram suas posições no interior da CA e mesmo que cada um tenha se responsabilizado por explanar sobre um tema, isso nem sempre aconteceu. O papel da coordenadora do grupo, ao direcionar atividades, poucas vezes foi ocupado por outros professores. Quando por alguma razão, não esteve presente, nem sempre foi dado o mesmo seguimento às práticas do grupo, o que indica que os demais professores não ocuparam outras posições no grupo. No entanto, ainda que observadas fragilidades na efetividade dos trabalhos de imaginação ou conexão de esforços a compreender a problemática ambiental de modo mais global, identificou-se movimento nas três características de uma CA, o que permitiu afirmar a relação de pertencimento dos professores ao grupo. "O trabalho é mais fecundo quando em uma CA, todos têm algo a ouvir e algo a dizer. Algo a aprender e algo a ensinar. Lugares de trocas e de reciprocidades de saberes, mas também de vidas e de afetos, onde a aula expositiva pode ser cada vez mais convertida no círculo de diálogos” (Brandão, 2005: 91).

Por fim, compreendeu-se que os professores pensaram sobre aprendizagem como uma experiência de identidade ao favorecer percursos possíveis, visíveis e compreensíveis. O processo de construção do conhecimento pela construção das atividades planejadas no grande grupo e desenvolvidas em pequenos grupos configurouse como contexto no qual se definiram identidades de participação de seus membros, como observado nos depoimentos de alguns dos participantes, quando afirmaram que: “ $a$ 
formação permanente é um processo de transformação, que vai acontecendo devagar" (Ana Maria) ${ }^{7}$. "Porque antes disso o professor está conformado com sua preparação" (Andréia). Ou ainda que "antes de participar do grupo estava preocupada só em passar os conteúdos” (Mararúbia); “muitas vezes não penso no que o aluno quer saber, porém, no grupo isso começa a me consumir” (Ana Maria).

Percebeu-se que o grupo analisado encontrava-se em movimento de se compreender mais intensamente como uma CA. Nessa perspectiva, conferiu-se a importância de os grupos de formação, diante das dimensões da prática de uma comunidade, promoverem situações para o engajamento mútuo, para a elaboração de materiais e experiências para se construir uma leitura de mundo e de si (repertórios compartilhados) e evidenciarem no empreendimento conjunto, o significado de suas ações. Compreendeu-se ainda que essa formação precisa ser pensada na proposição de atividades em que: a responsabilidade pela aprendizagem uns dos outros se torne o empreendimento conjunto da $\mathrm{CA}$, os desafios exijam conhecimentos que levem a explorar novos conhecimentos e que as ações tenham continuidade o suficiente para que os participantes desenvolvam práticas compartilhadas em seus empreendimentos conjuntos.

\section{BRICOLAGENS CONSTITUTIVAS NA FORMAÇÃO DE PROFESSORES EDUCADORES AMBIENTAIS}

A pesquisa realizada por Cupelli (2008) buscou compreender a formação do grupo de pesquisa CEAMECIM problematizando os sentidos sobre ser educador ambiental, ser professor ou mesmo ser professor educador ambiental.

A pesquisa pautou-se nas possibilidades de (re)invenção do presente através da produção de narrativas individuais e coletivas (Benjamin, 1994; Clandinin e Connelly, 2000; Bruner, 2001; 2003; Czarniawska, 2004; Galvão, 2005) em que, ao invés de se produzir um conhecimento sobre, prioriza-se a construção de (re)conhecimentos com os professores, o que Santos (2005) chama de conhecimento com.

7Foram usados nomes fictícios para identificação dos participantes do Grupo investigado 
Ao se considerarem os espaços formativos como únicos e imutáveis corre-se o risco de produzir essencializações, expressas no gasto "o professor deve". Essa é uma visão do pesquisador sobre o professor, na produção de um conhecimento que tem o outro como objeto e não como sujeito, o que Santos (2005) denomina de conhecimentoregulação. Por esse motivo, procurou-se produzir conhecimentos compartilhados, (re)conhecimentos, visando um conhecimento-emancipação. Em contrapartida ao conhecimento-regulação, que tem seu estado de saber no colonialismo, o conhecimentoemancipação tem como estado de saber a solidariedade.

Sem o objetivo de produzir verdades discursivas sobre o outro, a produção de (re)conhecimentos em uma comunidade interpretativa esteve voltada para o diálogo de saberes, sem julgar. Procurou-se um continuum das vivências do grupo. O que esteve em pauta foi a postura aberta para (re)colher, compartilhar e interpretar histórias e relatos em um movimento auto-hétero-formativo.

Durante oito meses, os professores, sujeitos da pesquisa, produziram (auto)relatos orais e escritos. Através desse dispositivo, contaram suas trajetórias formativas. Explicitaram suas certezas e dúvidas pessoais e profissionais. $\mathrm{O}$ pesquisador estava inserido nas atividades de formação continuada desses professores. Posteriormente, foram feitas cinco reuniões com o grupo para leitura e interpretação "com olhares cruzados" (Josso, 2006) dos (auto)relatos. A partir daí, o pesquisador escreveu as narrativas ficcionais para compartilhar os sentidos emergentes dessa comunidade.

Para (Reigota, 1999) as "narrativas ficcionais" foram, antes de qualquer outra coisa, uma maneira ética de lidar com as experiências dos ecologistas pelo mundo. Fato é que as narrativas, qualificadas como ficcionais, relevam, então, a necessidade de dizer o dito em surdina, tática para lidar com as sutilezas e detalhes das experiências vividas.

Nesta pesquisa consideraram-se as narrativas ficcionais como bricolagens constitutivas (Certau, 2005), resultados dos sentidos que emergiram ao longo da pesquisa, nos contextos formativos com professores educadores ambientais. Foram elas espectros de uma realidade arquitetada em um tom literário. Foram ficcionais, e qualquer semelhança com a realidade não terá sido mera coincidência. 
As narrativas suscitam sempre novos sentidos resultantes da combinação entre textos. Dessa forma, os textos são constantemente interrogados, produzindo ações. É como se a produção de uma narrativa estimulasse a produção de outra e assim por diante. Isso remete a questão de se pensar em comunidades interpretativas, como pode ser um grupo de professores em formação permanente. É o que argumentam (Bruner e Weisser, 1997: 156): “O que une as pessoas em uma comunidade é esse reconhecimento compartilhado, essa sensação de 'Eu sei que você sabe que eu sei o que você quer dizer'”.

Clandinin e Rosiek (2007) ao percorrerem um itinerário entre as possibilidades da narrativa em diferentes vertentes discursivas, situam-se na vertente crítica, indicando que as narrativas podem favorecer o fortalecimento mútuo entre uma e outra narrativa. A leitura de uma narrativa, por identificação pode produzir a produção da narrativa do leitor. Muitas vezes, se pode deixar de contar algo por achar que o que se tem a dizer não encontrará respaldo em um grupo maior de pessoas. Mas, quando se percebem semelhanças com a narrativa do outro, fortalecem-se ambas narrativas. Ou seja, a narrativa é uma maneira de lutar contra a "grande narrativa", e no caso desta pesquisa de dizer que há modos diversos de ser professor educador ambiental.

Como resultado da pesquisa, foram produzidas quatro narrativas ficcionais (Eco, 1997), das quais, neste texto, apresenta-se uma delas, a história intitulada "Mosaico: histórias de professores educadores ambientais".

\section{MOSAICO: histórias de professores educadores ambientais}

À sombra da pitangueira, no quintal da casa de Marta, reuniam-se nas tardes de sexta feira. Cultivavam ali um espaço de compartilhamento. Além das pitangas rubras e doces - que dividiam no mês de novembro -, contavam anedotas que viam pelas frestas da vida. Com o final do ano letivo, as coisas andavam turbulentas. Todos correndo para dar conta de cumprir as demandas. Notas a finalizar, trabalhos a serem lidos, e-mails se acumulando, projetos pedindo por relatórios. O caos era grande, mas não os impediu de estarem na última reunião do ano à sombra da pitangueira. Ainda mais que, sendo esta a última reunião do ano, como era de costume, faziam um amigo secreto. 
Próximo das duas e meia, Ana e Roberto tocaram a campainha da casa de Marta. Ela conferiu o bolo de maçã que estava no forno e caminhou apressadamente até a porta. Recebeu os dois com satisfação. Comentaram o atraso de Letícia. Será que ela não viria? Marta a chama no celular. Em poucos minutos ela bateu à porta.

Todos reunidos nos fundos da casa, Roberto tentava alcançar algumas pitangas remanescentes. Letícia comentava da possibilidade de escrevem em conjunto um trabalho para o II Encontro Regional de Práticas de Ensino e Educação Ambiental. Ela lembrava da dinâmica do evento, em que os professores discutiam seus relatos em círculos, construindo argumentações coletivas a partir de cada trabalho. Ana, muito propositiva, logo concordou com Letícia. Marta, em seguida, predispôs-se a trabalhar um bocadinho mais para dar conta da tarefa. Roberto, com uma das mãos tingida de vermelho, quis saber mais detalhes. Depois, achou que seria uma ótima ideia.

Continuaram a falar do trabalho. A ideia era escrever um relato da expedição de estudos que faziam em conjunto fazia anos. Nessa atividade, percorriam com seus alunos determinados espaços da cidade, buscando contextualizar conteúdos, problematizar questões socioambientais e intensificar o pertencimento desses alunos à sua região. Marta, que de uns tempos para cá experimentava alguns conflitos quanto ao seu modo de ser professora de Biologia, relembrou que a expedição de estudos teria de começar a ser mais propositiva.

Outras conversas seguiram.

$$
[\ldots]
$$

A história continua e aqui se apresentou apenas parte dela para marcar a intencionalidade de sua produção. Como seu nome indica - "Mosaico" - tem a intencionalidade de compor um painel formativo. O mosaico é interessante porque é feito com “colagens" de fragmentos (bricolagens) e o sentido (ou a imagem) é conferido, então, pela união e interpretação desses fragmentos em um contexto. Apostar em metáforas é uma maneira de vislumbrar algo para além do sentido dominante (Ricoeur, 1994; Gauthier, 2004). Os conceitos, apesar de sempre serem submetidos à prova, são restritivos, pois possuem um início e um fim delimitados. A metáfora é aberta, pois 
permite interpretações diversas e o compartilhamento de sentidos, multiplicando significados ao invés de limitá-los, embora a própria metáfora tenha nela mesma também seu limite.

Como repertório compartilhado em uma comunidade aprendente ressalta-se a narrativa ficcional como modo de apresentar resultados da construção de conhecimentos, partindo da crítica ao conhecimento-regulação. Defende-se a construção de conhecimentos emancipatórios que têm na solidariedade seu estado de saber. Salienta-se a comunidade interpretativa como locus da pesquisa, em uma interação interpretativa entre os participantes (professores educadores ambientais) e o pesquisador.

\section{AMBIENTALIZAÇÃO DE PROFESSORES DE QUÍMICA EM RODAS DE FORMAÇÃO}

Apresentam-se, nesta parte do texto, fragmentos de pesquisa de (Souza, 2010) realizada nos anos finais do curso de Química - Licenciatura, nos estágios curriculares quando os futuros professores assumem a sala de aula na rede básica de educação. Pretende-se evidenciar a intenção de escuta e acolhimento como característica de professores educadores ambientais em momentos de sala de aula, pautados pelo diálogo e pela afetividade. É na escuta atenta, no acolhimento, na partilha que professores se tornam professores educadores ambientais (Cascino, 1999).

No estágio curricular acompanhado por esta pesquisa cada licenciando assumiu integralmente a regência de uma turma de estudantes de Ensino Médio e produziu narrativas reflexivas semanais. Na solicitação para a produção das narrativas reflexivas das aulas dadas não havia intenção de controle sobre as atividades realizadas nas escolas, mas sim de que essas narrativas pela escrita se constituíssem em mais um espaço de formação, tanto do narrador quanto dos possíveis leitores. Este espaço de formação, por sua vez, implicou num movimento de vai e vem nas discussões nos encontros semanais na sala de aula da universidade (Lima, 2005), à medida que as narrativas eram produzidas a cada semana.

Cinco histórias - quadrados da Colcha, metáfora construída para expressar as aprendizagens nesta pesquisa - foram elaboradas, tendo o contexto do Estágio como 
espaço dialógico de formação permanente em que fragmentos de narrativas transitam, impregnando diálogos e constituindo enredos do que é contado. No âmbito deste trabalho apresenta-se como resultado apenas parte de uma destas histórias elaboradas a partir do que foi narrado pelos alunos - contar uma história de histórias contadas.

“O método não é senão o discurso dos passos andados” enfatiza (Marques, 2008: 114). Por conta disso, destaca-se que a opção pela construção das histórias pretendeu, parafraseando (Certeau, 1994: 46), "a proliferação de histórias e operações heterogêneas que compõem os patchworks do cotidiano". Se se admite que nas histórias, por um lado, os movimentos das Rodas expressam o olhar do narrador, por outro, o papel do leitor é significativo nessa "proliferação". Discorrendo a respeito da atividade leitora, (Certeau, 1994: 49) afirma que a mesma apresenta "todos os traços de uma produção silenciosa: flutuação através da página, metamorfose do texto pelo olho que viaja, improvisação e expectação de significados trazidos de certas palavras, intersecções de espaços escritos, dança efêmera".

Optou-se pela feitura de histórias a caracterizar, via recortes de narrativas de todos os envolvidos na Roda de Formação no estágio curricular (alunos e professores), as principais categorias emergentes do processo de análise. Estas categorias, que definiram as temáticas em que cada história estaria focada, foram: insegurança; tempos da escola; conteúdos; diálogo; afetividade; e identidade. Ricoeur (1994) fortalece a importância atribuída à elaboração das histórias e à perspectiva de fusão entre história e ficção ao mencionar que a narrativização não se diferencia da historiografia, argumentando que mesmo o historiador precisa interpretar e, nesse sentido, utilizar sua faculdade imaginativa. Por outro lado, o modo como se é afetado pelo que se lê pode ser pensado numa perspectiva de "autonomia do texto". Gentil (2004: 225) afirma que "através da leitura o leitor apropria-se do texto e é tomado pelo texto, entrega-se ao texto no ato de ler $[\ldots]$ ". Tocam-se aqui o mundo do texto e o mundo do leitor, saindo este último transformado desse encontro. Nesse sentido, o mesmo autor aponta que, numa perspectiva de mediação do texto que se instala entre o que o autor pretendeu expressar e 
o que seria compreendido pelo leitor, é o leitor quem atribui significados e, do ponto de vista da autonomia do texto, atualiza o que se pretendeu dizer.

Esta, portanto, é a expectativa em relação ao fragmento de história reproduzido a seguir, em que professores iniciantes, em rodas de formação, relatam suas impressões em suas primeiras aulas e os professores experientes escutam e acolhem essas falas. $\mathrm{Na}$ história que segue, resultante de quinze relatórios de estágio analisados segundo, se quer chamar atenção à escuta dos professores educadores ambientais aos alunos em rodas de formação nas suas primeiras aulas ao término de um curso de Licenciatura em Química, sendo essa a categoria a ressaltar como formadora de professores educadores ambientais mais do que o conteúdo de Química, terminalidade do curso em que esses professores educadores ambientais atuam.

\section{O PRIMEIRO DIA COMO É DIFÍCIL!}

"Esta é minha primeira aula efetivamente como professora da turma!"

"Último estágio! Mais alguns meses e estarei formada! Quem diria?"

Estes pensamentos perturbavam a tentativa de Raquel lembrar em que canto do quarto colocara seu casaco branco com capuz. Hoje voltaria tarde para casa, era agosto e “à noite sempre esfriava um pouco mais!", repetiu para si a frase que tantas vezes ouvira da mãe.

Mas do mesmo modo como aquele final de tarde ensolarada ia perdendo brilho com a chegada da noite, a satisfação da formatura que se anunciava era sufocada pela ansiedade que crescia à medida que o horário da aula se aproximava. Enquanto revisava as anotações da aula preparada com esmero, uma pergunta a incomodava: "Será que conseguiria dar conta de um semestre inteiro de estágio?”.

No trajeto do ônibus até a escola, relembrou o seu ingresso na licenciatura em Química e o desejo de ser professora, manifestado desde o início, nas primeiras conversas com alguns professores do curso. No curso de Magistério aprendera Química apenas no primeiro ano e assim mesmo só Química Geral, nada de Química Orgânica! Mas gostou de estudar a Química do cursinho e, apesar de ser o básico para o 
AMBIENTE \& EDUCAÇ̃̃o

ISSN- 1413-8638

E-ISSN - 2238-5533

v. 22, n. 2, p. 129-153, 2017

vestibular, deu um duro danado para aprender tudo sobre os hidrocarbonetos e as outras funções. O professor possuía qualidades que ela admirava: domínio, segurança, quadronegro impecável e sempre trazia para as aulas alguma curiosidade do cotidiano. Além disso, ensinava a matéria com muito orgulho e com rigor!

Imaginou que aquele era o jeito que ela gostaria de ter com seus alunos. "Pelo menos vou fazer o possível para isso!" Esses pensamentos foram interrompidos pela necessidade de atenção que o terreno irregular e a grama alta exigiam, quando desembarcou a cerca de vinte metros da entrada da escola.

Na sala dos professores ficou aguardando Ema, professora da turma. Cumprimentou timidamente as professoras que estavam por ali. Eram rostos desconhecidos. "Ainda bem - pensou - nenhuma delas se aproximou para conversar." Assim poderia dar uma última revisada no seu material da aula.

"O primeiro dia, como é dificil!" - disse para si mesma quando se dirigia para a sala de aula. Ema caminhava um pouco à frente e Raquel a seguia pelo corredor estreito, tentando distrair-se com fragmentos de conversas que atravessavam as paredes das salas que cruzavam:

Sentiu um aperto no peito quando pararam em frente à sala da sua futura turma, aguardando a saída da outra professora. Mal escutou as palavras de Ema, que percebendo a situação tentou aliviar a tensão:

- Vai dar tudo certo! Vais ver que esta é uma turma muito legal!

$$
[\ldots]
$$

Na Roda do estágio Raquel parecia ser a mais ansiosa em se manifestar. Havíamos combinado, no encontro anterior, que cada um contaria um pouco das suas primeiras semanas de aula. Tão logo iniciamos a rodada de relatos, em tom de desabafo ela diz:

- Está sendo complicado esse meu estágio. Me sinto constrangida quando escuto vocês falando das suas turmas e eu apenas com uma aula dada! E tenho tantas incertezas e inseguranças em relação à turma! Estou muito receosa com a próxima aula, pois o conteúdo que irei dialogar será sobre ligação química, em um período, e no 
período seguinte será a prova que a professora elaborou... Além disso, essa semana eu não dei aula na sexta porque teve um tumulto...

$O$ clima de descontração e tagarelices informais a respeito das atividades de todos nas escolas transformou-se rapidamente e o silêncio pontuou as escutas atentas e os olhares de cada um, fixos na expressão de choro contido. Antes mesmo de Raquel concluir sua fala muitos já ensaiavam movimentos de intervenções, como água da chuva acumulando na calha do telhado para, em seguida, inundar a vegetação rasteira do chão.

As histórias das pesquisas em parte aqui apresentadas continuam perpassadas pela partilha, pelo afeto e pelo acolhimento. Produzidas em Rodas de Formação produzem mosaicos feitos de bricolagens de experiências que nos tornam professores educadores ambientais em CA.

\section{CONSIDERAÇÕES FINAIS}

Ao finalizar este texto destaca-se a ampliação das ações a partir do que aprendemos como professores educadores ambientais nas CA. Outros tempos e espaços, outros grupos, outras Rodas de Formação sempre acontecendo. Alguns desses movimentos impregnando esta escrita enquanto fonte de inspiração - fragmentos de histórias, retalhos, quadrados, colcha, mosaicos... Colcha de Retalhos, sempre permeados por metáforas.

Argumenta-se que, permeando essas conversas nas Rodas, estão a escuta sensível e a partilha de saberes e fazeres que, entre outras coisas, constituem pressupostos desta ambientalização numa perspectiva processual e de acolhimento. E embora sabendo da relevância de enfoques curriculares que problematizem, por exemplo, a insustentabilidade de sociedades cujo "desenvolvimento" acontece associado à exclusão social e degradação ambiental, prestou-se mais atenção numa ambientalização que tem entre seus referenciais os fundamentos e princípios da pedagogia de Freire (2007). Neste referencial, a ambientalização do professor pressupõe respeito aos saberes dos educandos, criticidade, ética, autonomia, humildade, tolerância, alegria, esperança, bom senso, 
curiosidade, liberdade, autoridade, amorosidade, comprometimento, disponibilidade para o diálogo e aposta de que mudanças são possíveis.

\section{REFERÊNCIAS}

ALMEIDA, B. Concepções e ações de leitura de professores alfabetizadores em escolas do campo. In: Congresso de Leitura do Brasil, 14, Campinas. Anais... Campinas, SP: UNICAMP/ Associação de Leitura do Brasil. 1 CD ROOM, 2003.

ALMEIDA, B. Polifonia e Conhecimento: um estudo s/preliminar sobre a constituição de leitor em processo de formação permanente em professores do campo. IN: PINHEIRO, A.S. et al. (Orgs.). Educação, Currículo, Ensino e Formação de Professores. Francisco Beltrão: UNIOESTE, 2005p. 29-49.

ALMEIDA, B. A escrita na formação continuada de professoras alfabetizadoras: práticas de autoria. Tese (Doutorado) - Curso de Pós Graduação em Educação, Faculdade de Educação, Universidade de São Paulo, São Paulo, 2007.

BARTON, D.; TUSTING, K. Beyond Communities of Practice: language, power, and social context. New York: Cambridge, 2005.

BAUMAN, Z. Comunidade. Rio de Janeiro: Jorge Zahar, 2003.

BENJAMIN, W. Obras escolhidas. Magia e técnica, arte e política: ensaios sobre literatura e história da cultura. $7^{\mathrm{a}}$ ed. São Paulo: Brasiliense. - (Obras escolhidas; v. 1), 1994 .

BRANDÃO, C. R. Comunidades Aprendentes. In: FERRARO Jr., L. A. Encontros e Caminhos: formação de educadoras (es) ambientais e coletivos educadores. Brasília: Ministério do Meio Ambiente, 2005a, p. 85-92.

BRANDÃO, C. R. Aqui é onde eu moro, aqui nós vivemos: escritos para conhecer, pensar e praticar o município educador sustentável. 2a ed. Brasília: MMA, Programa Nacional de Educação Ambiental, 2005b.

BRUNER, J. A cultura da educação. Porto Alegre: Artmed editora, 2001. 
BRUNER, J. Making stories: law, literature, life. Harvard University Press, 2003.

BRUNER. J; W. S.. A invenção do ser: a autobiografia e suas formas. In: Olson, D. R.; Torrance, N.(Orgs.).p. 141-161. Cultura escrita e oralidade. São Paulo: Ática, 1997.

CASCINO, F. Educação Ambiental: princípios, história, formação de professores. São Paulo: Editora SENAC,1999.

CLANDININ, J.D; CONNELLY, M. Narrative Inquiry. San Francisco: Jossey-Bass Publishers, 2000.

CLANDININ, J.; ROSIEK, J. Mapping a landscape of narrative inquiry: borderland sapces and tensions. In: Clandinin, Jean (org.).p. 35-37. Handbook of narrative inquiry: mapping a methodology. University of Alberta, 2007.

COUSIN, C. S. Pertencer ao navegar, agir e narrar: a formação de educadores ambientais. Tese (Doutorado). Programa de Pós-graduação em Educação Ambiental. Universidade Federal do Rio Grande - FURG. Rio Grande, 2010.

CUPELLI, R. L. Inventar é (re)existir: a produção de sentidos na constituição de professores educadores ambientais. Dissertação (Mestrado). Fundação Universidade Federal do Rio Grande, Rio Grande, 2008.

CZARNIAWSKA, B. Reading narratives. In: CZARNIAWSKA, B. Narratives in social science research. p. 60-75. SAGE Publications, 2004.

DE CERTEAU, M. A Invensão do Cotidiano 1 - artes de fazer. Trad. E.F.Alves. Petrópolis: Vozes, 1994.

DEMO, P. Pesquisa: Princípio Científico e educativo. São Paulo: Cortês1991.

DEMO, P. $\boldsymbol{A}, \boldsymbol{B}, \boldsymbol{C}$ : iniciação à competência reconstrutiva do professor básico. Campinas: Papirus,1995a.

DEMO, P. Educação e Qualidade. 2ed. Campinas: Campinas: Papirus,1995b.

DEMO, P. Educar pela Pesquisa. Campinas: Autores Associados, 1996. 
DEMO, P. Pesquisa e Construção de Conhecimento: metodologia cientifica no caminho de Habermas. Rio de Janeiro: Tempo Brasileiro,1997.

DEMO, P. Questões para teleeducação. Petrópolis: Vozes,1998.

DEMO, P. Conhecer \& Aprender: sabedoria dos limites e desafios. Portos Alegre: Artmed,2000.

DIAS, G.F. Educação ambiental: princípios e práticas. São Paulo: Gaia,2003.

DUTRA, E. A narrativa como uma técnica de pesquisa fenomenológica. Estudos de Psicologia, v. 7, n.2,2002.

ECO, U. Seis passeios pelos bosques da ficção. São Paulo: Companhia das letras,1997.

FREIRE, P. Educação como prática da liberdade. 29. ed. Rio de Janeiro: Paz e Terra,2006.

FREIRE, P. Pedagogia do oprimido. 44. ed. Rio de Janeiro: Paz e Terra,2005.

FREIRE, P. Pedagogia da autonomia: saberes necessários à prática educativa. 36. ed. São Paulo: Paz e Terra,2007.

FREIRE, P.; FAUNDEZ, A. Por uma pedagogia da pergunta. Rio de Janeiro: Paz e Terra, 1985 .

HART, P. Narrativa, conhecimento e metodologias emergentes na pesquisa em Educação Ambiental: questões de qualidade. In: GALIAZZI, M. C. \& FREITAS, J. V. (Orgs.).p. 15 - 61. Metodologias emergentes de pesquisa em educação ambiental. Ijuí/RS:Unijuí, 2005.

GAliAZZI, M. C. Educar pela Pesquisa: Ambiente de formação de professores de ciências. Ijuí: UNIJUÍ, 2003.

GALVÃO, C. Narrativas em Educação. Ciência \& Educação, São Paulo: Unesp, v.11, n. 2, p. 327-345,2005. 
GAUTHIER, J. Z. A questão da metáfora, da referência e do sentido em pesquisas qualitativas: o aporte da sociopoética. In: Revista Brasileira de Educação. n. 24, p. 127142, jan./fev./mar./abr, 2004.

GENTIL, H. S. Para uma poética da modernidade: uma aproximação à arte do romance em Temps et Récit de Paul Ricoeur. São Paulo: Edições Loyola, 2004.

JOSSO, M-C. As figuras de ligação nos relatos de formação: ligações formadoras, deformadoras e transformadoras. In: Educação e pesquisa. São Paulo, v.32, n.2. p. 373383, maio/ago, 2006.

LARROSA, J. Notas sobre a experiência e o sabor da experiência. Revista Brasileira de Educação, vol. 19, p. 20-28, 2002.

LAVE, J.; WENGER, E. Situated learning: Legitimate peripheral participation. New York, Cambridge University Press,1991

LIMA, C. A. O diário em roda, roda em movimento: formar-se ao formar professores no Proeja. Tese (Doutorado). Programa de Pós-Graduação em Educação Ambiental. Universidade Federal do Rio Grande - FURG. Rio Grande/RS, 2011.

LIMA, M. E. C. C. Sentidos do trabalho - a educação continuada de professores. Belo Horizonte: Autêntica, 2005.

LOUREIRO, C. B. F. Educação Ambiental Transformadora. In: LAYRARGUES, P. (coord.). Identidades da Educação Ambiental Brasileira. Ministério do Meio Ambiente. Diretoria de Educação Ambiental. Brasília: Ministério do Meio Ambiente, 2004.

LOUREIRO, C. B. F. Trajetória e fundamentos da Educação Ambiental. 2a Ed. São Paulo: Cortez, 2006.

MARQUES, M. O. Escrever é Preciso: o princípio da pesquisa. Petrópolis: Vozes, 2008. MORAES, R.; RAMOS, M. G; GALIAZZI, M. C. A epistemologia do aprender no educar pela pesquisa em ciências: alguns pressupostos teóricos. In: MORAES, R.; 
MANCUSO, R. (Org). Educação em ciências: produção de currículos e formação de professores. Ijuí: Ed.Unijuí, p. 85 - 108, 2004.

MORAES, R.; GALIAZZI, M. C. Análise Textual Discursiva. Ijuí: Ed. Unijuí, 2007.

OLSON. D. R. The world on paper: the conceptual and cognitive implications of writing and reading. New York: Cambridge University Press, 1994.

OLSON. D. R. A escrita e a mente. In: Wertsch, J.; Del Rio, P.;Alvarez, A. p.89-111. Estudos socioculturais da mente. Porto Alegre: ArtMed,1998.

ORELLANA, I. La estrategia pedagógica de la comunidad de aprendizaje definiendo sus fundamentos, sus prácticas y su pertencia en educación ambiental. In: SAUVÉ, L.; ORELLANA, I.; SATO, M. (Dir.). p. 221 - 231. Sujets choisis en éducation relative à I'environnement - D'une Amérique à I'autre. Montréal: ERE - UQAM, Tome II, 2002. REIGOTA, M. Ecologistas. Santa Cruz do Sul: EDUNISC, 1999.

RICOEUR, P. Tempo e narrativa; tradução Constança Marcondes Cesar. Campinas, SP: Papirus, 1994.

SAlomÃo DE FREITAS, D. P. A Perspectiva da Comunidade Aprendente nos Processos Formativos de Professores Pesquisadores Educadores Ambientais. 2010. Dissertação (Mestrado) - Programa de Pós-Graduação em Educação Ambiental, Universidade Federal do Rio Grande - FURG, Rio Grande,2010.

SANTOS, B. S. Da ciência moderna ao novo senso comum. In: SANTOS, B.S. p. 1-117. A crítica da razão indolente: contra o desperdício da experiência. Para um novo senso comum: a ciência, o direito e a política na transição paradigmática Vol.1. 5. ed. São Paulo: Cortez, 2005.

SOUZA, M. L. Histórias de constituição e ambientalização de professores de química em rodas de formação em rede: colcha de retalhos tecida em partilhas (d)e narrativas. Tese (Doutorado) - Programa de Pós-Graduação em Educação Ambiental, Universidade Federal do Rio Grande - FURG, Rio Grande, 2010. 
ST. CLAIR, R. Education Research as a Community of Practice. In: KIMBLE, C.; HILDRETH, P.; BOURDON, I. (ed.). Communities of Practice: Creating, Learning, Environments for Educators. Charlotte: Information Age Publishing, Inc. Cap. 2, p. 2138. (vol. 1),2008.

VYGOTSKY, L. Pensamento e Linguagem. São Paulo: Martins Fontes,1991.

WARSCHAUER, C. Rodas em rede: oportunidades formativas na escola e fora dela. Rio de Janeiro: Paz e Terra,2001.

WELLS, G. Dialogic inquiry: toward socialcultural practice and theory of Education. New York: Cambridge University Press, 1999.

WENGER, E. Communities of Practice: Learning, Meaning, and Identity. 2 reimpressão. New York: Cambridge University,2001

YUS, R. As comunidades de aprendizagem na perspectiva holística. In: Pátio Revista Pedagógica. Porto Alegre: Artmed, 2002. 